\title{
Subcellular and Subsynaptic Localization of Presynaptic and Postsynaptic Kainate Receptor Subunits in the Monkey Striatum
}

\author{
Jeremy Z. Kieval, G. W. Hubert, Ali Charara, Jean-François Paré, and Yoland Smith \\ Division of Neuroscience, Yerkes Regional Primate Research Center, and Department of Neurology, Emory University, \\ Atlanta, Georgia 30322
}

\begin{abstract}
The localization and functions of kainate receptors (KARs) in the CNS are still poorly known. In the striatum, GluR6/7 and KA2 immunoreactivity is expressed presynaptically in a subpopulation of glutamatergic terminals and postsynaptically in dendrites and spines. The goal of this study was to further characterize the subcellular and subsynaptic localization of kainate receptor subunits in the monkey striatum. Immunoperoxidase data reveal that the relative abundance of GluR6/7- and KA2immunoreactive terminals is homogeneous throughout the striatum irrespective of the differential degree of striatal degeneration in Huntington's disease. Pre-embedding and post-embedding immunogold data indicate that $>70 \%$ of the presynaptic or postsynaptic GluR6/7 and KA2 labeling is expressed intracellularly. In material stained with the post-embedding immunogold method, approximately one-third of plasma membrane-bound gold particles labeling in axon terminals and spines is associated with asymmetric synapses, thereby representing synaptic kainate
\end{abstract}

Glutamate is the major excitatory neurotransmitter in the CNS. Its activity is mediated by three groups of ionotropic receptors: NMDA, AMPA, and kainate receptors (KARs). Kainate receptors are comprised of five subunits, GluR5, 6, 7, and KA1-2 (Hollmann and Heinemann, 1994). Until a few years ago, the inability to pharmacologically differentiate AMPA from KA receptors had limited the understanding of a distinct functional role of KARs in the CNS. However, the use of novel benzodiazepine compounds (GYKI compounds), which act as selective antagonists of AMPA receptors (Paternain et al., 1995), has provided a means of demonstrating a distinct role of KARs in modulating synaptic transmission. Interestingly, several in vitro electrophysiological and pharmacological studies have shown that KARS mediate presynaptic effects on GABAergic and glutamatergic neurotransmission in various brain regions (Clarke et al., 1997; Lerma et al., 1997; Rodriguez-Moreno et al., 1997; Mulle et al., 1998; Rodriguez-Moreno and Lerma, 1998; Chittajallu et al., 1999; Liu et al., 1999; Min et al., 1999; Perkinton and Sihra, 1999; Chergui et al., 2000; Contractor et al., 2000; Frerking and Nicoll, 2000; Kamiya and Ozawa, 2000). Furthermore, the excitotoxic

\footnotetext{
Received Feb. 23, 2001; revised Aug. 6, 2001; accepted Sept. 5, 2001.

This work was supported by a grant from the United States Army and the National Institutes of Health base grant of Yerkes Regional Primate Research Center (RR 00165). We thank Maney Mazloom and James Weeks for technical assistance, Frank Kiernan for photography, and Peggy Plant for clerical work. Thanks are also due to Beth Richardson for her help and advice to use the high pressure freezer.

Correspondence should be addressed to Yoland Smith, Yerkes Regional Primate Research Center, 954 Gatewood Road Northeast, Emory University, Atlanta, GA 30322. E-mail: yolands@rmy.emory.edu.

Copyright (C) 2001 Society for Neuroscience $\quad 0270-6474 / 01 / 218746-12 \$ 15.00 / 0$
}

receptor subunits. On the other hand, $>60 \%$ of the plasmamembrane bound labeling is extrasynaptic. Both GluR6/7 and KA2 labeling in glutamatergic terminals often occurs in clusters of gold particles along the membrane of large vesicular organelles located at various distances from the presynaptic grid. Anterograde labeling from the primary motor cortex or the centromedian thalamic nucleus indicate that both corticostriatal and thalamostriatal terminals express presynaptic GluR6/7 and KA2 immunoreactivity in the postcommissural putamen. In conclusion, these data demonstrate that kainate receptors in the striatum display a pattern of subcellular distribution different from other ionotropic glutamate receptor subtypes, but consistent with their metabotropic-like functions recently shown in the hippocampus.

Key words: Huntington's disease; excitotoxicity; presynaptic receptor; corticostriatal pathway; thalamostriatal pathway; post-embedding immunogold

effects of KAR agonists were found to be greatly reduced in the CA3 region of the rat hippocampus after mossy fiber denervation (Debonnel et al., 1989). Similar results of decreased susceptibility to kainate-induced seizures and cell death have recently been shown in mutant mice knock-outs of the GluR6 gene (Mulle et al., 1998), providing evidence that these excitotoxic effects are produced through the activation of presynaptic KARs.

Huntington's disease (HD) is an autosomal dominant neurodegenerative disorder characterized by a massive death of striatal projection neurons. In $>60 \%$ of HD patients, increasing length of CAG repeats correlates highly with a decrease in the age of onset of the disease or the extent of striatal degeneration (Persichetti et al., 1994; Aronin et al., 1995; Penney et al., 1997). However, recent findings have reported that the variance in the age of onset of HD could also be attributed to mutations in the gene encoding the GluR6 KAR subunit (Rubinsztein et al., 1997; MacDonald et al., 1999). Injections of kainic acid into the striatum have, indeed, been known to cause cell death in striatal projection neurons, but to have no such effect on axons crossing or terminating in the area (Coyle and Schwarcz, 1976; McGeer and McGeer, 1976). The fact that these neurotoxic effects of kainate in the striatum are attenuated after decortication (McGeer et al., 1978; Biziere and Coyle, 1979), implies that these effects are mediated via cortical terminal glutamate release. In line with these observations, recent findings from our laboratory have demonstrated the presence of KAR immunoreactivity on glutamatergic nerve terminals in the monkey striatum (Charara et al., 1999). To further extend these data and better understand the functions of kainate receptors in the primate striatum, the aim of the present study is to elucidate the 
subcellular and subsynaptic localization of the GluR6/7 and KA2 KAR subunits in the monkey striatum.

The findings presented in this study have been published in abstract form (Kieval et al., 2000).

\section{MATERIALS AND METHODS}

\section{Animals and preparation of tissue}

Four male adult rhesus monkeys and two male adult squirrel monkeys were used in the present study. The two squirrel monkeys were used for tracing studies (see below), whereas the four rhesus monkeys were processed for KAR immunocytochemistry. After deep anesthesia with an overdose of pentobarbital, rhesus monkeys were perfusion-fixed with $500 \mathrm{ml}$ of cold oxygenated Ringer's solution followed by 21 of fixative containing $4 \%$ paraformaldehyde and $0.1-0.75 \%$ glutaraldehyde in phosphate buffer (PB; $0.1 \mathrm{M}, \mathrm{pH}$ 7.4). The anesthesia and perfusion of the animals were performed in accordance with the NIH Guide for the Care and Use of Laboratory Animals (1996) and the Emory University Animal Care and Use Committee. The brains were then cut in $60-\mu$ m-thick sections with a vibrating microtome and processed for the immunohistochemical localization of GluR6/7 and KA2 at the electron microscopic level. A series of sections were cut at $100 \mu \mathrm{m}$ and processed for the freeze substitution technique and post-embedding immunogold localization of GluR6/7 and KA2 receptor subunits as described below.

\section{Kainate receptor antisera}

Commercially available affinity-purified polyclonal antisera generated against synthetic peptides corresponding to the $\mathrm{C}$ terminus of GluR6 (TFNDRRLPGKETMA) (Upstate Biotechnology, Lake Placid, NY) and KA2 (GPTGPRELTEHE) (Upstate Biotechnology) were used in this study. The specificity of the anti-GluR6 and anti-KA2 antibodies was determined by immunoblots of cell membranes from transfected human embryonic kidney cells (HEK 293 cells) (Petralia et al., 1994; Wenthold et al., 1994). Immunoblot analyses showed that these antibodies label a single band that corresponds to the molecular weight of their respective receptor subunit. However, as a result of the sequence homology at the C terminus between the GluR6 and the GluR7 subunits, the antibody to GluR6 also recognizes the GluR7 subunit to some degree; hence, the term GluR6/7 for this antiserum. To confirm that the sequence of amino acids of the synthetic peptides used to produce these antibodies are not found in other known proteins, we performed a search for amino acids sequence alignment in the basic local alignment search tool (BLAST) database (Altschul et al., 1997), and we found that there was no significant cross-reactivity with any proteins other than the GluR6/7 and KA2 kainate receptor subunits. This search also revealed that the amino acids sequences used are found in GluR6/7 and KA2 subunits of both rats and humans, suggesting that these antibodies should recognize their corresponding antigenic sites in both primates and nonprimates.

The specificity of the two antisera was further confirmed in the present study by the complete lack of labeling in sections of monkey striatum incubated in solutions from which the antisera were replaced by either nonimmune rabbit serum or antiserum that has been preadsorbed with 10 $\mu \mathrm{g} / \mathrm{ml}$ homologous peptides for $1 \mathrm{hr}$ at room temperature (Fig. $1 B, D$ ). Immunoblotting was also performed to test the specificity of the GluR6/7 antiserum on monkey striatal tissue (Fig. 2). The Western blot procedure was performed as follows: samples of protein were subjected to SDSPAGE and transferred by electroblotting onto polyvinylidene fluoride membranes (Invitrogen, Carlsbad, CA). The blots were blocked with 5\% nonfat dry milk, $0 . \%$ Tween 20 in Tris-buffered saline (TBS) $(20 \mathrm{~mm}$ Tris- $\mathrm{HCl}$ plus $137 \mathrm{~mm} \mathrm{NaCl}, \mathrm{pH} 7.4$ ) at room temperature for $1 \mathrm{hr}$, and then incubated overnight at $4^{\circ} \mathrm{C}$ with antibodies raised against the $\mathrm{C}$ terminus of the GluR6/7 subunit $(0.5 \mu \mathrm{g} / \mathrm{ml}$; Upstate Biotechnology) in blocking buffer. The blots were then rinsed for $20 \mathrm{~min}$ in blocking buffer and incubated for $1 \mathrm{hr}$ in horseradish peroxidase-conjugated goat antirabbit IgG (Bio-Rad, Hercules, CA), diluted 1:10,000 in blocking buffer. After several washes in TBS, the immunoreactive proteins were visualized with enhanced chemiluminescence (Amersham Pharmacia Biotech, Buckinghamshire, UK). For preadsorption experiments, antibodies were preadsorbed with $10 \mu \mathrm{g} / \mathrm{ml}$ homologous peptide for $1 \mathrm{hr}$ at room temperature.

\section{Electron microscope KAR immunocytochemistry}

Pre-embedding immunoperoxidase. Sections prepared for pre-embedding immunoperoxidase were pretreated with sodium borohydride $(1 \%$ in
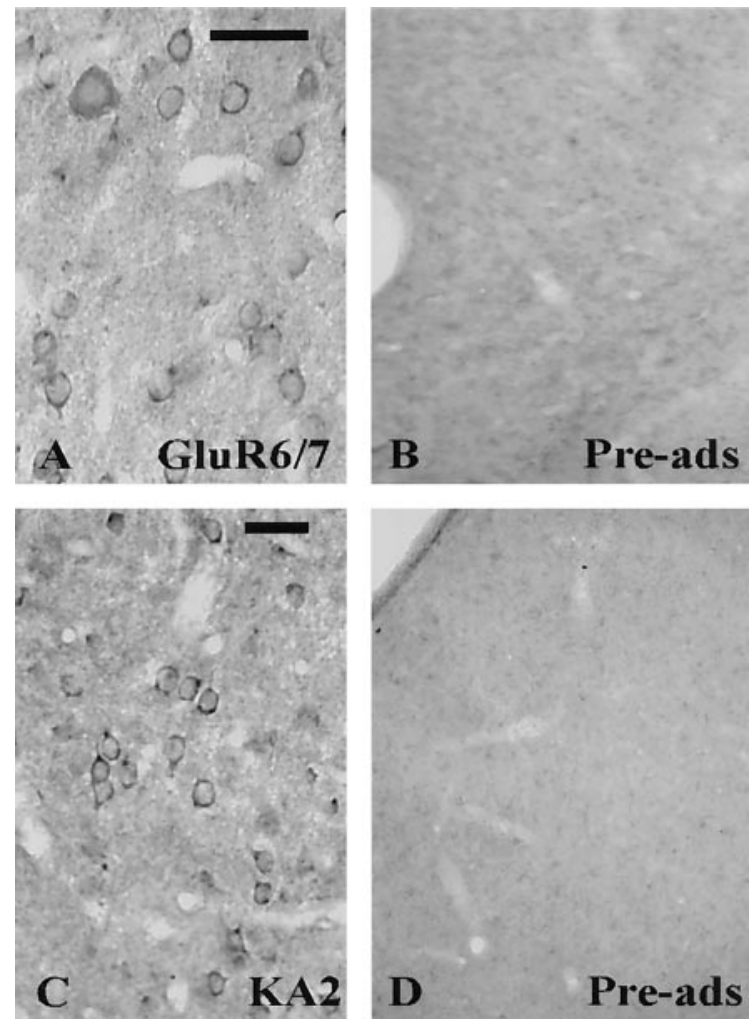

Figure 1. Controls for the specificity of GluR6/7 $(A, B)$ and KA2 $(C, D)$ antisera on monkey striatal tissue. In $B$ and $D$, the antisera were preadsorbed with $10 \mu \mathrm{g} / \mathrm{ml}$ of homologous peptides for $1 \mathrm{hr}$ before incubation. Scale bars: $A, 50 \mu \mathrm{m}$ (valid for $B$ ); $C, 50 \mu \mathrm{m}$ (valid for $D$ ).

\section{GluR6/7 Preadsorbed}

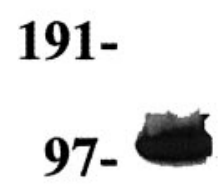

\section{4-}

Figure 2. Western blot analysis demonstrating the specificity of the GluR6/7 antiserum. The antibodies detected a single band that corresponds to the approximate molecular weights predicted for GluR6 and GluR7 subunits ( $\sim 18 \mathrm{kDa})$. Immunoreactivity is completely abolished when antibodies are preadsorbed with the synthetic GluR6/7 peptide $1 \mathrm{hr}$ before immunoblotting. Molecular weight standards are indicated on the left $\left(10^{3}\right.$ molecular weight $)$.

PBS; $0.01 \mathrm{~m} ; \mathrm{pH} 7.4$ ) and then cryoprotected in a solution of $25 \%$ sucrose and $10 \%$ glycerol before being frozen at $-80^{\circ} \mathrm{C}$ for $20 \mathrm{~min}$. They were then thawed and returned to a graded series of cryoprotectant and PBS. Afterward, sections were preincubated in $10 \%$ normal goat serum (NGS) in PBS for $1 \mathrm{hr}$, followed by incubation for $48 \mathrm{hr}$ at $4^{\circ} \mathrm{C}$ in rabbit polyclonal antisera (GluR6/7, $7.5 \mu \mathrm{g} / \mathrm{ml}$; KA2, $0.55 \mu \mathrm{g} / \mathrm{ml})$ diluted in PBS supplemented with $1 \%$ NGS. After three 10 min washes in PBS, the sections were incubated in biotinylated goat anti-rabbit IgG (1:200; Vector Laboratories, Burlingame, CA) for $90 \mathrm{~min}$ at room temperature, which was followed by three 10 min washes in PBS. Incubation in the avidin-biotin-peroxidase complex (ABC; 1:100; Vector Laboratories) (Hsu et al., 1981) subsequently followed for a period of $90 \mathrm{~min}$. After two 10 min washes in PBS and one 10 min wash in TRIS buffer $(0.05 \mathrm{M}, \mathrm{pH}$ 
7.6), the immunostaining was revealed by incubation for $10 \mathrm{~min}$ in a solution containing $0.025 \% \quad 3,3^{\prime}$-diaminobenzidine tetrahydrochloride (DAB; Sigma, St. Louis, MO), 0.01 M imidazole (Fisher Scientific, Atlanta, GA), and $0.006 \%$ hydrogen peroxide $\left(\mathrm{H}_{2} \mathrm{O}_{2}\right)$. The reaction was stopped by repeated washes in PBS.

Pre-embedding immunogold. Sections processed for pre-embedding immunogold were prepared as described in previous studies (Hanson and Smith, 1999). In brief, sections were pretreated with sodium borohydride, cryoprotected, and frozen at $-80^{\circ} \mathrm{C}$ in the same manner as those processed for immunoperoxidase. They were then preincubated in $10 \%$ NGS in PBS containing $0.5 \%$ bovine serum albumin, $0.05 \%$ Tween 20 , and $0.1 \%$ gelatin (PBS-BSA) for $1 \mathrm{hr}$. This was followed by an overnight incubation at room temperature in the primary antibody solution diluted as described above. After three 10 min washes in PBS-BSA, the sections were incubated in goat anti-rabbit IgG conjugated to $1.4 \mathrm{~nm}$ colloidal gold particles (1:100 in PBS-BSA; Nanogold; Nanoprobes, Stony Brook, $\mathrm{NY}$ ) for $2 \mathrm{hr}$ at room temperature. After a $5 \mathrm{~min}$ wash in PBS-BSA and two 5 min washes in PBS, the sections were post-fixed in $1 \%$ glutaraldehyde in PBS for $10 \mathrm{~min}$ at room temperature. After washing in PB (0.1 $\mathrm{M}, \mathrm{pH}$ 7.4) for $5 \mathrm{~min}$, the gold labeling was intensified by using a silver enhancement kit (HQ silver; Nanoprobes) for 5-10 min at room temperature in the dark and stopped by several washes in distilled water.

\section{Anterograde labeling of corticostriatal and thalamostriatal afferents}

Two squirrel monkeys received bilateral iontophoretic injections of biotinylated dextran amine (BDA) either in the primary motor cortex or the centromedian $(\mathrm{CM})$ intralaminar thalamic nucleus. After being intubated and anesthetized with isoflurane, the animals were fixed in a stereotaxic frame, and intracerebral injections of BDA were performed according to procedures described in details in many of our previous studies (Shink et al., 1996; Sidibé and Smith, 1996; Sidibé et al., 1997). In brief, the BDA was injected for 20 min through glass micropipettes with a tip diameter ranging from 20 to $50 \mu \mathrm{m}$ using a $6 \mu \mathrm{A}$ positive current delivered at a $7 \mathrm{sec}$ ON/7 sec OFF cycle. Two injection sites along a single penetration were made in $\mathrm{CM}$, whereas a total of 10 injection sites along eight penetrations were made in the cerebral cortex. The depth of anesthesia was monitored throughout the surgery by measuring hearth rate, blood oxygen level, and toe pinch reflex. After surgery, animals received systemic injections of analgesic for $48 \mathrm{hr}$. The surgical and anesthesia procedures used in these experiments are consistent with those of the National Institute of Health and approved by the Institutional Animal Care and Use Committee of Emory University. After 7-10 d survival, the animals were deeply anesthetized with sodium pentobarbital and perfused transcardially as described above for rhesus monkeys, except that the volumes of Ringer's and fixative were reduced to $350 \mathrm{ml}$ and 11 , respectively.

\section{$B D A$ histochemistry combined with KAR immunocytochemistry}

The BDA was revealed with the ABC method as described in previous studies. In brief, after sodium borohydride treatment, cryoprotection, and $-80^{\circ} \mathrm{C}$ freezing, sections were washed in PBS and incubated overnight at room temperature in standard $\mathrm{ABC}$ complex (1:100 dilution). The peroxidase bound to the BDA was then localized with DAB as described above for KAR immunoperoxidase localization. Once the BDA has been revealed, striatal sections that contained large amount of anterogradely labeled fibers were processed for the pre-embedding immunogold localization of GluR6/7 and KA2 as described above. Doublelabeled sections were then prepared for electron microscopy.

As controls, a series of sections were processed to reveal BDA followed by incubation in solution containing nonimmune rabbit serum rather than KAR antisera.

Preparation for electron microscopy. All sections prepared for electron microscopy were washed in $\mathrm{PB}(0.1 \mathrm{M}, \mathrm{pH} 7.4)$ before being post-fixed in osmium tetroxide (1\% solution in PB) for 10-20 min. They were then washed five times ( 5 min each) in PB and dehydrated in a graded series of alcohol and propylene oxide. Uranyl acetate was added to the $70 \%$ ethanol to improve the contrast in the electron microscope. The sections were then embedded in resin (Durcupan, ACM; Fluka, Buchs, Switzerland) on microscope slides and put in the oven for $48 \mathrm{hr}$ at $60^{\circ} \mathrm{C}$. After examination in the light microscope, areas of interest in the striatum were cut out from the slides and glued on top of resin blocks with cyanoacrylate glue. Ultrathin 60-nm-thick sections were cut on a Leica (Nussloch, Germany) UCT ultramicrotome and collected on pioloform-coated, sin- gle slot copper or gold grids. Some sections were stained with lead citrate (Reynolds, 1963) and examined with a Zeiss EM10C electron microscope.

High-pressure freezing, freeze substitution, and post-embedding immunogold technique for KAR localization. Tissue from the putamen and the head of the caudate nucleus from three rhesus monkeys were used in this study. After cryoprotection, small areas of $2 \mathrm{~mm}$ in diameter were taken from $100-\mu \mathrm{m}$-thick striatal sections and placed between two aluminum planchettes that were then instantly frozen in liquid nitrogen using a high-pressure freezer (Balzers HPM 010). Sections were stored in liquid nitrogen until transfer into a freeze substitution apparatus (Bal-Tec FSU 010) whereby the temperature was increased from -90 to $-45^{\circ} \mathrm{C}$ in four major steps over a period of $30 \mathrm{hr}$. The specimens were freezesubstituted in $0.5 \%$ uranyl acetate dissolved in methanol and then embedded in Lowicryl $\mathrm{HM}-20\left(-45^{\circ} \mathrm{C}\right)$ in a low temperature polymerization unit (Bal-Tec LTPU 010) for $48 \mathrm{hr}$. Ultrathin 80-nm-thick sections were cut on a Leica UCT ultramicrotome and collected on pioloformcoated, 400 mesh gold grids.

Sections of freeze-substituted material were first treated in a saturated solution of sodium hydroxide in $100 \%$ ethanol ( $<1 \mathrm{sec}$.). After being washed in Tris-buffered saline containing $0.01 \%$ Triton X-100 (TBS-T), they were incubated for $10 \mathrm{~min}$ on drops of $0.1 \%$ sodium borohydride and $0.05 \mathrm{M}$ glycine diluted in TBS-T. They were then washed in TBS-T and preincubated for $30 \mathrm{~min}$ in TBS-T containing $10 \%$ normal serum and $2 \%$ human serum albumin (HSA) before being incubated overnight at room temperature with the GluR6/7 $(15 \mu \mathrm{g} / \mathrm{ml})$ and KA2 $(5.5 \mu \mathrm{g} / \mathrm{ml})$ antisera diluted in a solution of TBS-T containing $1 \%$ normal serum and $2 \%$ HSA. After many washes in TBS-T, the grids were incubated for $90 \mathrm{~min}$ in the $10 \mathrm{~nm}$ gold-conjugated secondary antibodies (1:180; BBInternational) diluted in TBS-T containing 1\% normal serum and 2\% HSA. Grids were washed in ultrapure water and contrasted in a $1 \%$ aqueous solution of uranyl acetate for $90 \mathrm{~min}$. The grids were then stained with lead citrate (Reynolds, 1963) before observation.

Control sections were incubated in solutions from which the primary antisera were replaced by $1 \%$ nonimmune rabbit serum, whereas the rest of the protocol remained the same as described above.

\section{Analysis of material}

Immunoperoxidase data. To estimate the relative abundance of GluR6/7and KA2-immunoreactive elements in different striatal regions, a series of 50 electron micrographs were taken at $16,500 \times$ from randomly chosen areas of the tail and body of the caudate nucleus, the putamen, and the nucleus accumbens in three monkeys. These micrographs covered a total surface of $7148 \mu \mathrm{m}^{2}$ of striatal tissue in each animal. All micrographs were taken from tissue on the surface of the blocks where the intensity of labeling was optimal. In each micrograph, immunoreactive elements were categorized as unmyelinated axons, terminals, spines, or small and large dendrites based on the following ultrastructural features. The unmyelinated axons were distinguished by their small diameter $(0.1-0.2$ $\mu \mathrm{m})$, regular contours, lack of synaptic inputs, and presence of microtubules, whereas axon terminals contained synaptic vesicles and did not receive synaptic inputs. The heads of dendritic spines were recognized by their electron lucent and bulbous appearance, lack of mitochondria, and absence of microtubules. They also frequently received asymmetric synaptic inputs. Finally, most dendrites were easily distinguishable from other neuronal elements by their large size and enrichment in mitochondria and microtubules. Elements that could not be categorized according to these ultrastructural features were not considered in the analysis. The mean percentage of labeled elements in each category was then calculated, and $\chi^{2}$ tests were performed to compare the relative abundance of immunoreactive terminals in the different striatal regions.

Pre-embedding immunogold data. In tissue immunostained with the pre-embedding immunogold technique, the proportion of gold particle labeling associated with the plasma membrane and intracellular compartments was calculated from a series of 200 electron micrographs taken at $25,000 \times$ in the putamen and the head of the caudate nucleus in three monkeys. These micrographs covered a total surface of $2843 \mu \mathrm{m}^{2}$ of striatal tissue. To avoid false-positive data generated by light background staining, an element had to contain, at least, three gold particles to be considered immunoreactive. The total number of gold particles in each immunoreactive element encountered in these micrographs was then calculated and categorized as intracellular or bound to the plasma membrane. Taking into consideration the size of primary and secondary antibodies, the maximum distance between the $1.4 \mathrm{~nm}$ gold particle and the epitope would be $\sim 17 \mathrm{~nm}$ (Blackstad et al., 1990). Based on this 
criterion, presynaptic or postsynaptic gold particle labeling was categorized as plasma membrane-bound if it was found inside an area not further than $16 \mathrm{~nm}$ plus radius of gold particles from the presynaptic or postsynaptic plasma membranes, respectively. All other gold particles were categorized as "intracellular". To avoid problems in categorizing the membrane-bound gold particles, only those elements that displayed good ultrastructural preservation with well preserved plasma membrane were considered.

Post-embedding immunogold data. This method was used to characterize the subsynaptic localization of GluR6/7 and KA2 labeling. The advantages of this approach over the pre-embedding immunogold technique to label synaptic receptors have been discussed in details in previous studies (Lujan et al., 1996; Ottersen and Landsend, 1997). In brief, the fact that the entire cut length of the plasma membrane is uniformly exposed to the antibodies increases the accessibility to the antigenic sites, which provides a condition for quantitative analysis of synaptic receptor localization. Quantitative measurements were made from a series of 100 electron micrographs taken at $31,500 \times$ from putamen and caudate tissue immunostained with GluR6/7 and KA2 by the post-embedding immunogold method. Because the quality of ultrastructural preservation of post-embedding immunostained tissue on the same grid is variable, we chose immunostained areas where the preservation was optimal for this analysis. To verify whether the pattern of distribution of immunogold labeling was the same as that found with the pre-embedding immunogold technique, we counted the total number of gold particles in a series of labeled terminals and spines and determined the proportion that were bound to the plasma membrane or intracellular. Furthermore, we categorized the plasma membrane-bound gold particles as "synaptic" or "extrasynaptic" based on their respective localization to synapses. A gold particle was categorized synaptic if it was located inside an area not further than $21 \mathrm{~nm}$ (antibody bridges, $16 \mathrm{~nm}$; radius of $10 \mathrm{~nm}$ gold particles, $5 \mathrm{~nm}$ ) from the presynaptic or postsynaptic plasma membrane (Matsubara et al., 1996; Valtschanoff and Weinberg, 2001; Nyiri et al., 2001). All other plasma membrane-bound gold particles were put in the extrasynaptic category. We used an arbitrary criterion that an element had to contain at least three gold particles or more to be considered immunoreactive.

To verify whether the distribution of presynaptic labeling displayed any relationship with the synaptic active zones, a series of immunostained terminals for GluR6/7 or KA2 were randomly selected for measurement of the shortest distance of individual gold particles from the presynaptic plasma membrane. To do so, we measured the distance that separated any gold particles bound to vesicular organelles from the closest part of the presynaptic membrane.

Anterograde labeling and pre-embedding immunogold labeling. Five blocks of striatal tissue (three for CM labeling, two for M1 labeling) immunostained for GluR6/7 or KA2 and BDA were chosen for this analysis. In the electron microscope, sections from the surface of the blocks were scanned for the presence of BDA-labeled terminals. Once such boutons were found, they were photographed at low $(12,500 \times)$ and high $(31,500 \times)$ magnification and categorized as double labeled if they contained three gold particles or more. To avoid false-negative data because of the poor penetration of the gold-conjugated secondary antibodies in tissue, only those BDA-containing terminals that were found in the vicinity of other non-BDA-labeled KAR-immunoreactive boutons were considered in this analysis.

\section{RESULTS}

\section{Tests for antibody specificity}

As previously shown (Charara et al., 1999), both GluR6/7 and KA2 immunoreactivities were found in numerous neuronal perikarya that displayed morphological features of both mediumsized projection neurons and large interneurons throughout the monkey striatum (Fig. 1A,C). After preadsorption of either antisera with homologous peptides, the striatum was completely devoid of immunostaining (Fig. 1B,D). Similar results were obtained after omission of the two primary antisera from the incubation solutions. Furthermore, a single band of labeling that corresponds to the molecular weight of GluR6 and GluR7 (Wenthold et al., 1994) was found in Western blots analysis of monkey striatum (Fig. 2). This band was completely abolished after preadsorption of the antiserum with homologous peptides (Fig. 2).

\section{Relative distribution of GluR6/7 and KA2-immunoreactive elements in the striatum}

Tissue from three rhesus monkeys was processed for immunoperoxidase to characterize the general distribution of GluR6/7 and KA2 immunoreactivity in different striatal regions. The goal of this first series of experiments was to determine whether the relative abundance of kainate receptor subunit-immunoreactive glutamatergic terminals correlate with the sensitivity of the different striatal regions to neurodegeneration in HD (Vonsattel and DiFiglia, 1998). To do so, we characterized the nature of labeled elements in striatal areas known to be more or less sensitive to neurodegeneration in HD. The tail and body of the caudate nucleus as well as the dorsal putamen were chosen as sensitive areas, whereas the nucleus accumbens served as the least sensitive region (Vonsatell and DiFiglia, 1998). In all striatal regions, the pattern of distribution and intensity of immunoreactivity for the two antibodies was consistent with previous data from our laboratory (Charara et al., 1999). KAR immunoreactivity was expressed presynaptically in small unmyelinated axons and axon terminals forming asymmetric axospinous and axodendritic synapses. The postsynaptic labeling was found predominantly in small dendrites, whereas labeled spines were much less abundant (Fig. 3). Both medium-sized and large neuronal perikarya also displayed light patchy immunoreactivity (data not shown; Charara et al., 1999). Overall, 20-40\% of GluR6/7containing striatal elements were axon terminals, whereas the proportion of KA2-immunoreactive boutons ranged from 10 to $15 \%$ (Fig. 3). Although there was a slight variation in the relative abundance of labeled terminals among the four striatal regions examined, these changes were not significantly different, which indicates that presynaptic KARs are homogeneously distributed throughout the striatum irrespective of the degree of sensitivity to degeneration in HD.

\section{Subcellular localization of kainate receptor subunit immunoreactivity}

\section{Pre-embedding immunogold}

Because of the poor spatial resolution of the immunoperoxidase deposit, this approach is not suitable to analyze the subcellular and subsynaptic localization of receptors. To overcome this problem we used pre-embedding and post-embedding immunogold procedures that allow to determine more precisely the exact localization site of receptors.

Overall, the pattern of pre-embedding immunogold labeling was consistent with that of the immunoperoxidase data, i.e., gold particles were mostly found in dendrites and axon terminals, although light immunoreactivity was occasionally seen in dendritic spines (Figs. 4, 5). In both large and small neuronal perikarya, gold particles were primarily expressed intracellularly in vesicular and tubular intracellular organelles that likely correspond to parts of endoplasmic reticulum and Golgi apparatus, whereas the plasma membrane was almost completely devoid of immunoreactivity (Fig. 4). To study the subcellular localization of KARs, randomly selected fields of immunoreactive elements were photographed in the putamen and the caudate nucleus of three monkeys. The gold particles were then counted and categorized as intracellular or plasma membrane-bound according to criteria described in Materials and Methods. One of the striking feature that characterized the localization of KAR subunit immunoreactivity was that $>70 \%$ of GluR6/7 and KA2 labeling was expressed intracellularly in all labeled elements (Figs. 4, 5, Table 1). In terminals, most gold particles were homogeneously distrib- 


\section{GluR6/7 Distribution}

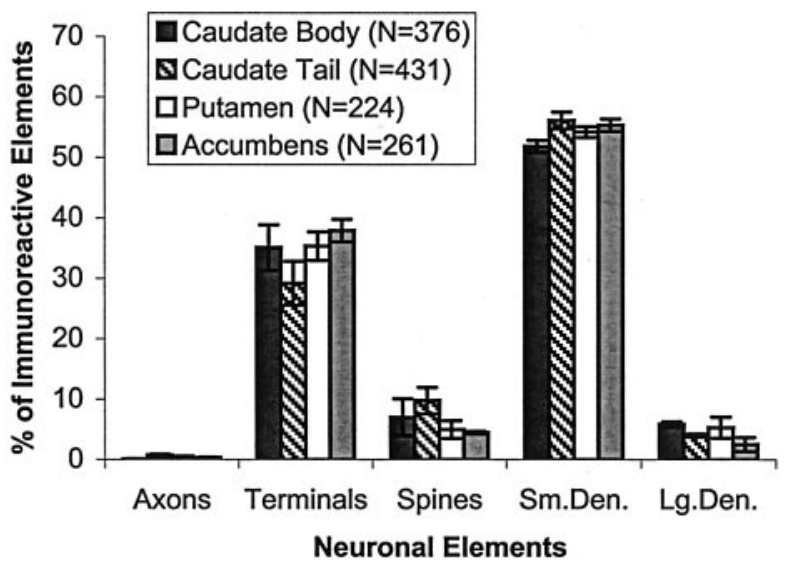

KA2 Distribution

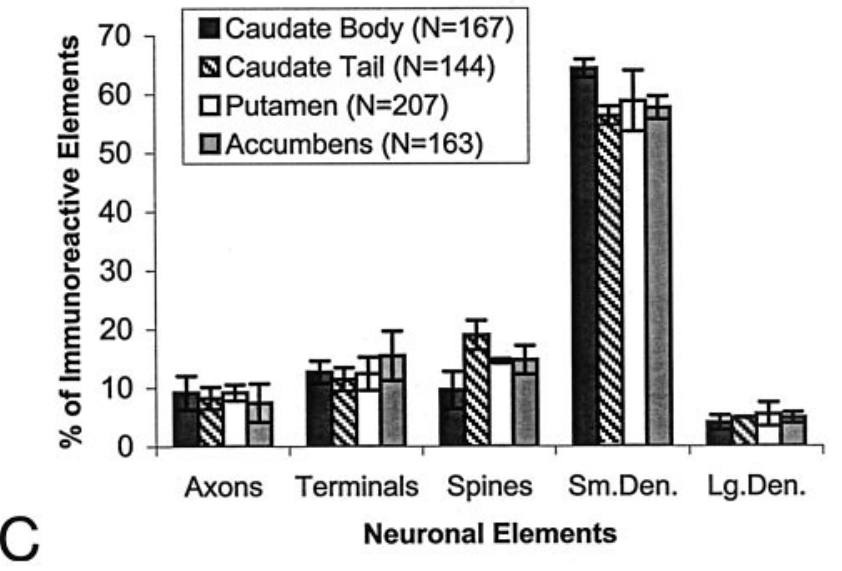

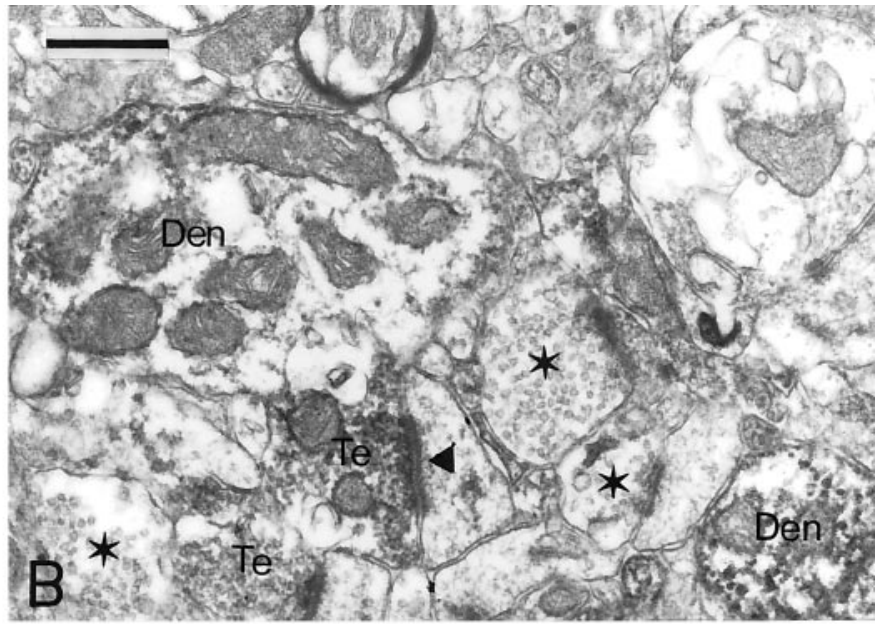

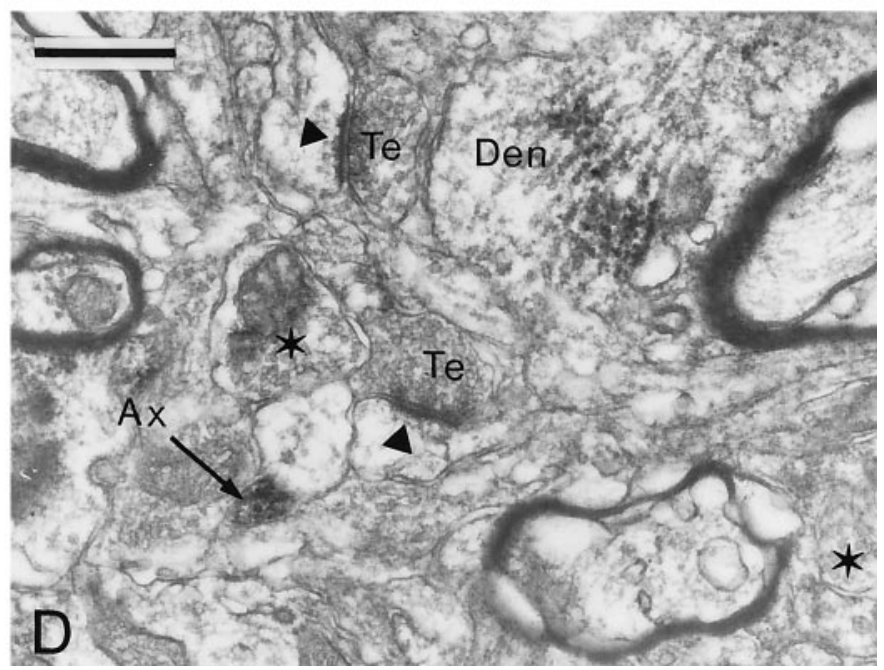

Figure 3. Relative distribution of GluR6/7 and KA2 immunoreactivity in different striatal regions. $A$, Histogram showing the relative proportion of neuronal elements immunoreactive for GluR6/7 in different striatal regions. B, GluR6/7-immunoreactive elements in the body of the caudate nucleus. Note the presence of labeled terminals (Te) forming asymmetric synapses (arrowheads) and immunoreactive dendrites (Den). The asterisks indicate unlabeled boutons. $C$, Histogram showing the relative distribution of neuronal elements immunoreactive for KA2 in different striatal regions. $D$, KA2-containing elements in the body of the caudate nucleus. Two immunoreactive terminals $(T e)$, a labeled dendrite (Den), and an unmyelinated axon $(A x)$ are shown. The asterisks indicate unlabeled boutons. Statistical analysis revealed no significant difference in the relative abundance of GluR6/7 or KA2-containing elements among the different striatal regions $\left(\chi^{2} ; p<0.001\right)$. Scale bars, $0.5 \mu \mathrm{m}$.

uted over synaptic vesicles, although dense aggregates of three or more particles were occasionally seen (Fig. 5). Because of the large size of silver-intensified gold particles, the exact localization site of presynaptic labeling was difficult to ascertain. Similarly, the ultrastructural preservation of intracellular organelles in dendrites and spines was not good enough to determine the exact binding site of intracellular postsynaptic gold labeling (Fig. 5).

\section{Post-embedding immunogold}

Because of the large size of silver-intensified gold particles and poor penetration of gold-conjugated antibodies through thick sections, the pre-embedding immunogold technique provides limited information on the quantitative distribution of subsynaptic antigenic sites. To gain a higher level of spatial resolution and quantitative estimates of the relative distribution of GluR6/7 and KA2 receptor subunit immunoreactivity at the synaptic level, the freeze-substitution post-embedding immunogold technique was performed on striatal tissue. Overall, the distribution of labeling was consistent with results obtained with the pre-embedding immunogold and immunoperoxidase methods (Fig. 6), i.e., gold particles were seen over axon terminals forming asymmetric synapses, unmyelinated axons, as well as postsynaptic dendrites and spines. In contrast, terminals forming symmetric synapses were completely devoid of labeling. To further ascertain that most of the GluR6/7 and KA2 immunoreactivity was expressed intracellularly, as revealed by the pre-embedding immmunogold technique (Table 1), we quantified the density of post-embedding immunogold labeling associated with intracellular elements versus the plasma membrane in a series of spines and axon terminals with good ultrastructural preservation in GluR6/7- and KA2immunostained material (Table 1). These data revealed that more than two-thirds of both presynaptic and postsynaptic GluR6/7 or KA2 labeling is expressed intracellularly in the monkey striatum (Table 1). However, a main difference between data obtained with the pre-embedding and post-embedding methods relates to the density of synaptic labeling for GluR6/7 and KA2. Although very few gold particles were associated with synapses in material prepared with the pre-embedding immunogold technique (Figs. 4, 5), 30-40\% of post-embedding immunogold label- 

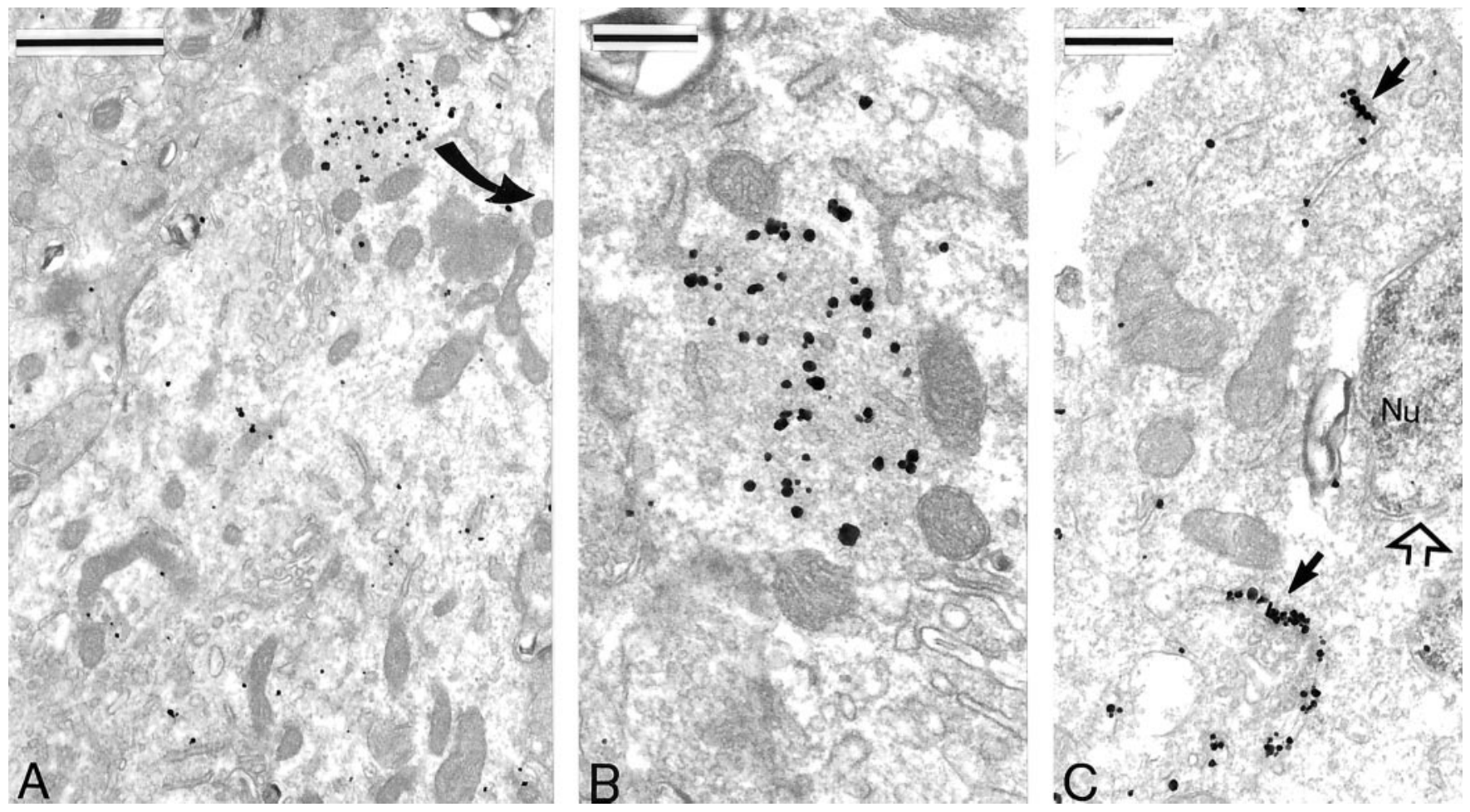

Figure 4. GluR6/7 and KA2 immunoreactivity in neuronal perikarya. A, A GluR6/7-containing neuronal perikaryon in the putamen. B, High magnification of gold particles labeling associated with the endoplasmic reticulum $(E R)$ in this cell body. $C$, KA2 immunoreactivity in Golgi or ER-like tubular organelles in a neuronal perikaryon (arrows) of an interneuron (invaginated nuclear membrane; open arrow). Nu, Nucleus. Scale bars: $A$, $1.0 \mu$ m; $B, 0.25 \mu \mathrm{m} ; C, 0.5 \mu \mathrm{m}$.

Table 1. Relative distribution of intracellular versus plasma membrane-bound immunogold particle labeling for GluR6/7 and KA2 as revealed by pre-embedding and post-embedding immunogold method

\begin{tabular}{llll} 
KAR subunits/ & \multicolumn{1}{l}{$\%$ Intracellular/plasma membrane-bound } & \\
\cline { 2 - 4 } neuronal elements & Spines & Terminals & Dendrites \\
\hline GluR6/7 & $71 / 29(n=237)$ & $74 / 26(n=526)$ & $78 / 22(758)$ \\
$\quad \begin{array}{l}\text { Pre-embedding } \\
\text { Post-embedding }\end{array}$ & $76 / 24(n=99)$ & $81 / 19(n=168)$ & - \\
KA2 & $76 / 24(n=144)$ & $77 / 23(n=97)$ & $75 / 25(n=492)$ \\
Pre-embedding & $75 / 25(n=93)$ & $73 / 27(n=182)$ & - \\
Post-embedding & & & - \\
\hline
\end{tabular}

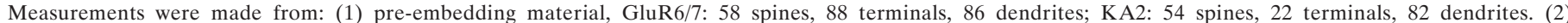

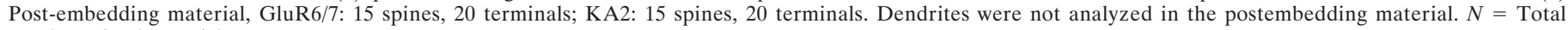
number of gold particles.

ing in spines and $20-30 \%$ of labeling in terminals was considered synaptic (Table 2). This difference in synaptic labeling between the pre-embedding and post-embedding immunogold methods has been previously described for other types of glutamate and GABA-A receptors (Baude et al., 1993; Nusser et al., 1995a,b). The poor penetration of gold-conjugated secondary antibodies through thick sections likely represents the main limiting factor of the pre-embedding immunogold method to label synaptic receptors.

As mentioned above, subsets of axon terminals forming asymmetric synapses display strong immunoreactivity for KAR subunits which, for the most part, was found to be expressed intracellularly over synaptic vesicles. The post-embedding immunogold method allowed to better characterize this presynaptic labeling and revealed that the majority of gold particles in terminal boutons were often clustered along the membrane of large vesicular organelles that were randomly distributed in the terminal (Fig. 6D,F). In addition, clusters of gold particles were occasionally seen in the presynaptic grid of asymmetric synapses (Fig. 6B,E).

To verify the relationships between presynaptic KARs and the synaptic release sites of glutamate, we measured the shortest distance between GluR6/7 and KA2 presynaptic immunogold particles bound to vesicular organelles and the synaptic active zone in 15 immunoreactive axon terminals immunostained with each antibodies (Fig. 7). These measurements indicate that both KAR subtypes display a wide range of distribution in relation to asymmetric synapses; some gold particles being found right at the active zones (Figs. 6B,E, 7) others being located as far as $1.0 \mu \mathrm{m}$ away from the synaptic junctions (Figs. 6D,F, 7). Control grids were devoid of labeling except for a few scattered gold particles. 

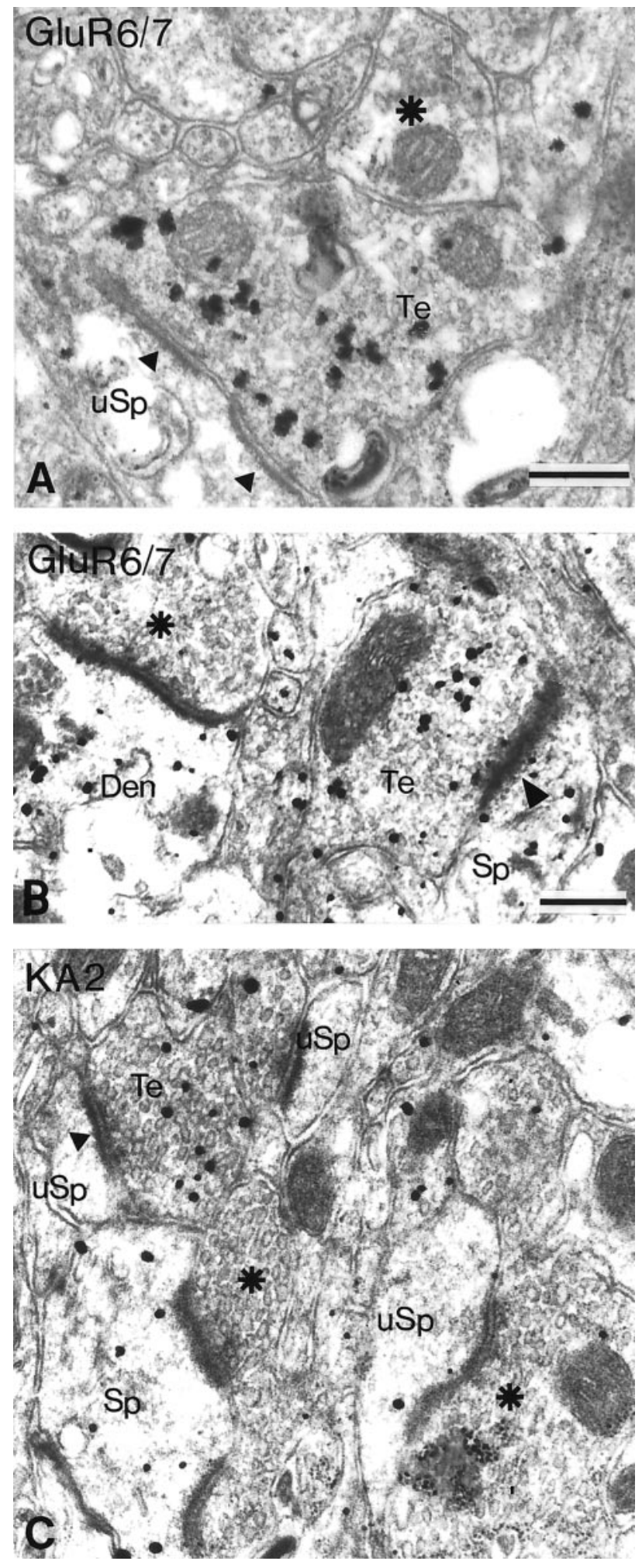

Figure 5. GluR6/7-immunoreactive $(A, B)$ and KA2-immunoreactive $(C)$ elements in the striatum as revealed with the silver-intensified preembedding immunogold method. $A, B$, GluR6/7-containing axon terminals $(\mathrm{Te}$ ) forming asymmetric axospinous synapses (arrowheads) in the caudate nucleus. Nonimmunoreactive terminals $(*)$ and unlabeled spines $(u S p)$ are shown in the same region. Labeled dendrites (Den) and spines $(S p)$ are indicated. $C$, A KA2-immunoreactive terminal $(T e)$ in the putamen. Nonimmunoreactive boutons $(*)$ and spines $(u S p)$ are shown in the same field. Note that most gold particles in axon terminals, dendrites $(D e n)$, and spines are located intracellularly. Scale bars: $A, 0.25 \mu \mathrm{m} ; B$, $0.25 \mu \mathrm{m}$ (valid for $C$ ).

\section{Sources of immunoreactive terminals}

Because both cortical and thalamic afferents provide glutamatergic terminals forming asymmetric synapses in the monkey striatum (Sadikot et al., 1992; Smith et al., 1994), we tested whether KAR subunits were associated with both glutamatergic inputs. Injections of BDA were made in the centromedian nucleus of the thalamus or the primary motor cortex in two squirrel monkeys. The thalamic injection sites were confined to $\mathrm{CM}$ with slight contamination of the overlying mediodorsal nucleus and the subparafascicular nucleus, whereas the cortical injections mostly involved the leg and trunk areas of M1 (Fig. 8). As expected based on previous studies (Sadikot et al., 1992; Smith et al., 1994), both injections produced large amount of anterograde labeling in fibers and axon terminals in the postcommissural putamen. In sections double-labeled for GluR6/7 or KA2 and BDA, 30-60\% of anterogradely labeled terminals (DAB-stained) displayed KAR subunit immunoreactivity (Table 3). The double-labeled boutons were easily distinguishable from unlabeled terminals in the same field by the coexpression of dense amorphous DAB reaction product (BDA labeling) overlaid by three gold particles or more (KAR labeling) (Fig. 9). Although the relative abundance of KA2-containing terminals was quite similar after thalamic and cortical injections, the proportion of GluR6/7containing thalamostriatal boutons was higher than corticostriatal terminals (Table 3).

\section{DISCUSSION}

This study provides the first detailed analysis of the subcellular and subsynaptic localization of kainate receptor subunits in the CNS. Four major conclusions can be drawn from our data: (1) kainate receptor-containing glutamatergic terminals are homogeneously distributed throughout the monkey striatum irrespective of the differentital sensitivity of striatal regions to Huntington's disease, (2) presynaptic and postsynaptic kainate receptor subunits are primarily expressed intracellularly in cell bodies, dendrites, spines and axon terminals throughout the striatum, (3) the majority of presynaptic and postsynaptic plasma membranebound immunogold labeling for GluR6/7 and KA2 is found extrasynaptically, although approximately one-third is also associated with asymmetric synapses, and (4) both thalamic and cortical terminals in the sensorimotor striatum express presynaptic KAR subunits. These results will now be discussed in light of previous functional studies of kainate receptors in the CNS and their potential implication in the progressive death of striatal neurons in HD.

\section{Presynaptic kainate receptors are homogeneously distributed in the striatum}

The immunoperoxidase data presented in this study extend previous findings of our laboratory showing that presynaptic kainate receptors are expressed in a subpopulation of putative glutamatergic boutons in the monkey striatum (Charara et al., 1999). In this study we tested the hypothesis that the relative abundance of KAR-containing terminals was greater in areas that are more sensitive to neurodegeneration in HD. It has, indeed, been shown that variation of the GluR6 subunit genotype is correlated with the age on onset of HD that cannot be accounted for by the number of CAG repeats (Rubinsztein et al., 1997; MacDonald et al., 1999). These observations, combined with the fact that some striatal regions are more sensitive than others to neurodegeneration, led us to consider the possibility that this particular pattern of neuronal death might be 

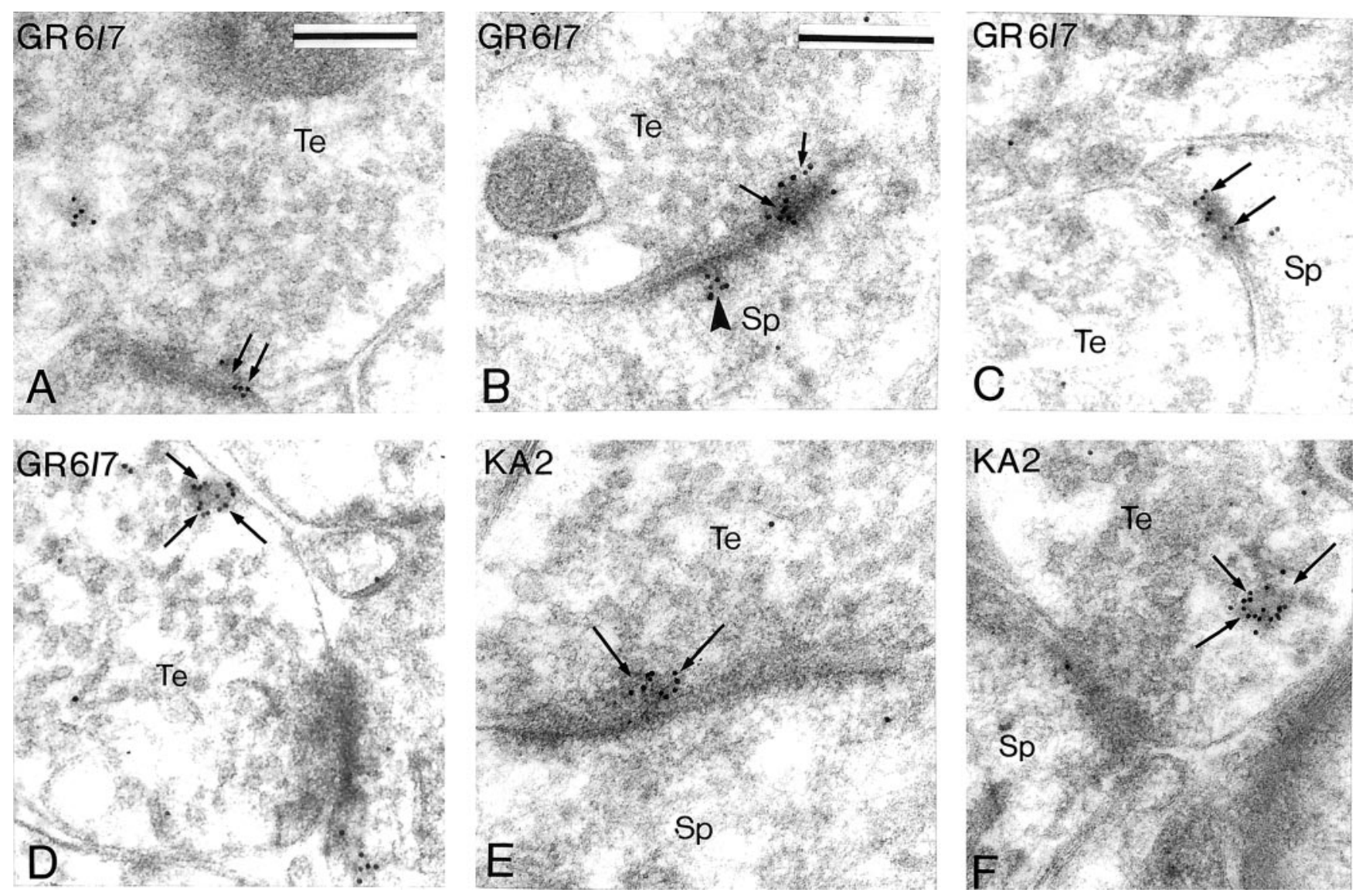

Figure 6. Post-embedding immunogold localization of GluR6/7 $(A-D)$ and KA2 $(E, F)$ immunoreactivity in the striatum. $A$, $C$, GluR6/7 labeling (double arrows) in the active zone of asymmetric axospinous synapses. $B$, Presynaptic and postsynaptic GluR6/7 labeling at an asymmetric axospinous synapse. $D$, Presynaptic GluR6/7 immunoreactivity along the surface of a large vesicular structures (arrows) in a terminal forming an asymmetric synapse with a spine. Note that gold particles in the axon terminal are aggregated at the presynaptic grid (arrows), whereas the spine labeling is associated with the postsynaptic density of the asymmetric postsynaptic specialization (arrowhead). E. Dense KA2 labeling (arrows) in the presynaptic grid of an asymmetric axospinous synapse. $F$, KA2 labeling (arrows) along the surface of a large vesicular organelle in an axon terminal apposed to a spine ( $S p$ ). Scale bars: $A, 0.25 \mu \mathrm{m}$ (valid for $C, D, F) ; B, 0.25 \mu \mathrm{m}$ (valid for $E$ ).

Table 2. Proportion of synaptic versus extrasynaptic immunogold labeling for kainate receptor subunits at asymmetric synapses in the striatum

\begin{tabular}{lll} 
KAR subunits/ & \multicolumn{2}{l}{$\%$ Synaptic/extrasynaptic gold labeling } \\
\cline { 2 - 3 } neuronal elements & Spines & Terminals \\
\hline GluR6/7 & $38 / 62(n=345)$ & $22 / 78(n=974)$ \\
KA2 & $43 / 57(n=112)$ & $29 / 71(n=345)$
\end{tabular}

Measurements were made from: GluR6/7, 56 spines; 77 terminals; KA2, 33 spines, 31 terminals. $N=$ Total number of gold particles.

attributable to a differential distribution of KAR-containing terminals throughout the striatum. We, therefore, hypothesized that areas like the tail of the caudate nucleus, which degenerates first in HD, contains more KAR-positive terminals than the nucleus accumbens, which remains intact in $>50 \%$ of HD patients (Vonsatell and DiFiglia, 1998). Our data revealed that such is not the case. We did not find any significant difference in the relative abundance of KAR-positive terminals between the tail of the caudate nucleus and other striatal regions. Of course, these data do not rule out the possibility that the malfunctioning of kainate receptors might underlie the pattern of striatal neurodegeneration in HD. However, if such is the case, this is unlikely to rely on a simple difference in the relative abundance of presynaptic kainate receptors in the different striatal regions. Variation in the GluR6 genotype might rather lead to changes in pharmacological and physiological properties of particular subsets of kainate receptors expressed presynaptically in specific striatal regions.

\section{Subcellular localization of kainate receptor subunits}

An interesting feature that characterized the subcellular localization of both GluR6/7 and KA2 receptor subunits is their strong intracellular expression. Our data demonstrate that $>70 \%$ of both presynaptic and postsynaptic KAR subunit immunoreactivity is expressed intracellularly and that almost two-thirds of the plasma membrane-bound KARS are extrasynaptic. This pattern of distribution resembles that of G-protein-coupled metabotropic receptors which, for the most part, are expressed intracellularly or at nonsynapic sites along plasma membrane (Pasquini et al., 1992; Wang et al., 1997; Bernard et al., 1999; Hanson and Smith, 1999; Smith et al., 2000, 2001). Interestingly, both the presynaptic and postsynaptic effects of kainate receptors are consistent with those of metabotropic glutamate receptor functions (for review, see Conn and Pin, 1997; Anwyl, 1999; Cartmell and Schoepp, 2000). For instance, kainate receptors mediate slow postsynaptic cur- 

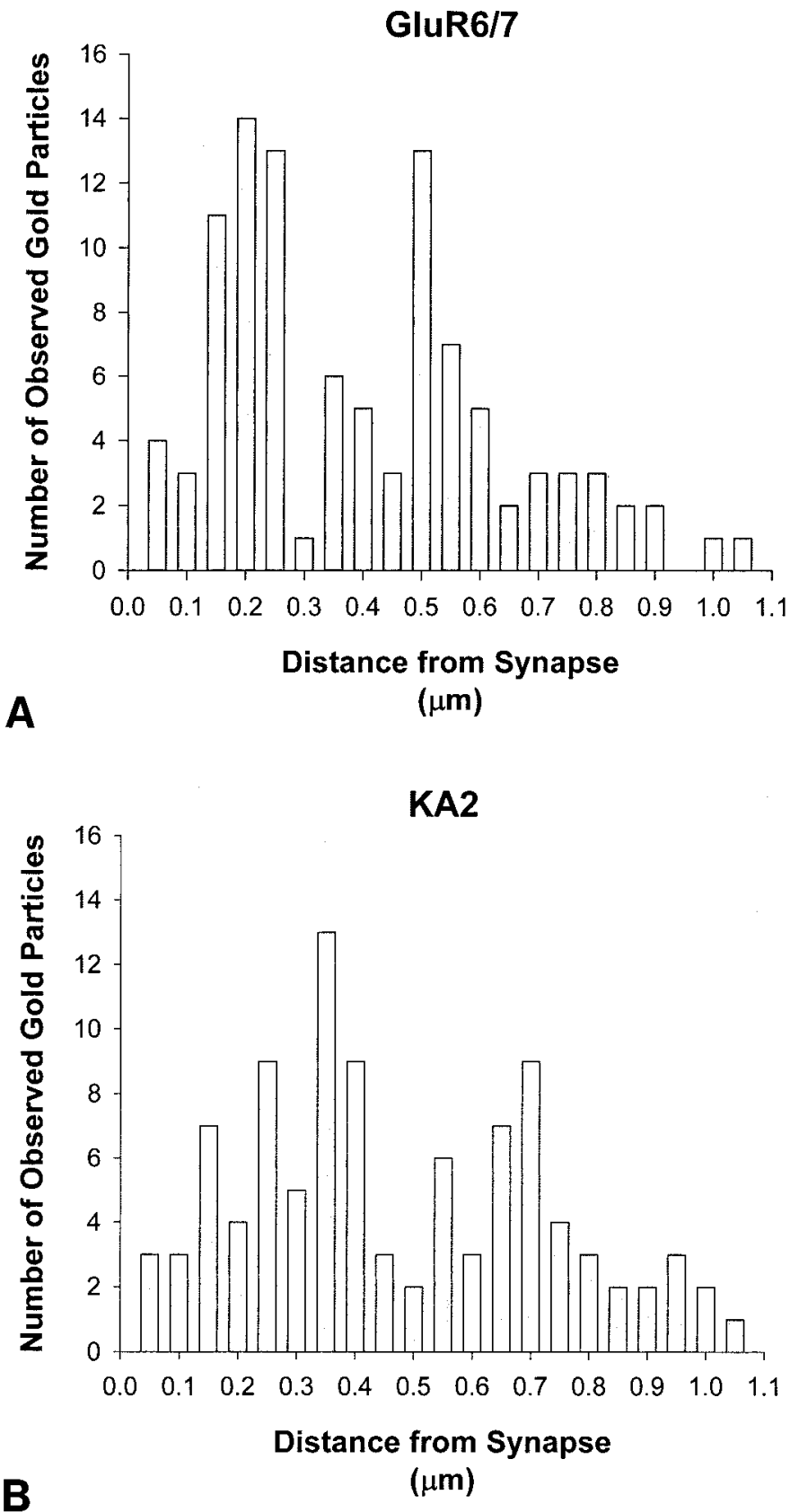

Figure 7. Histograms showing the distribution of gold particle labeling for GluR6/7 $(A)$ and KA2 $(B)$ in relation to the presynaptic grids of asymmetric synapses in the putamen. The mean $( \pm \mathrm{SD})$ shortest distance of gold particles from the active zones is relatively similar for both KAR subunits antibodies $(0.40 \pm 0.20 \mu \mathrm{m}$ for GluR6/7; $0.47 \pm 0.25 \mu \mathrm{m}$ for KA2). Fifteen terminals immunoreactive for GluR6/7 or KA2 were examined.

rents that could be elicited only after high-frequency stimulation of hippocampal mossy fiber pathway in CA3 pyramidal neurons in rats (Castillo et al., 1997; Vignes and Collingridge, 1997; Rodriguez-Moreno and Lerma, 1998). Furthermore, it has been shown that the presynaptic control of GABA release by kainate receptors in the hippocampus is mediated by a metabotropic process that is sensitive to Pertussis toxin and independent of ion channel current (Rodriguez-Moreno and Lerma, 1998). These functional data combined with results of our study clearly indicate that both the localization and functions of kainate receptors are

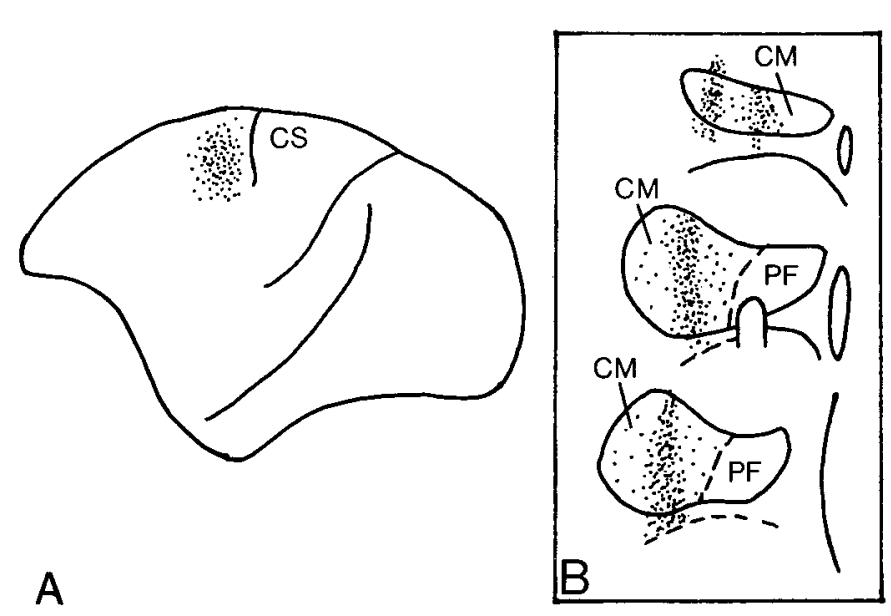

Figure 8. BDA injection sites in the primary motor cortex $(A)$ and the centromedian nucleus $(B)$ in squirrel monkeys. $C M$, Centromedian nucleus; $C S$, central sulcus; $F R$, fasciculus retroflexus; $P F$, parafascicular nucleus.

Table 3. Kainate receptor subunit immunoreactivity in anterogradely labeled thalamic and cortical terminals in the putamen

\begin{tabular}{lll} 
& \multicolumn{2}{l}{ Kainate receptor subunit immunoreactivity } \\
\cline { 2 - 3 } Sources of terminals & GluR6/7 $(\%)$ & KA2 $(\%)$ \\
\hline CM & $60(N=55)$ & $40(N=42)$ \\
M1 & $28(N=58)$ & $43(N=51)$ \\
\hline$N=$ Total number of anterogradely labeled terminals examined.
\end{tabular}

$N=$ Total number of anterogradely labeled terminals examined.

strikingly different from those of conventional ionotropic glutamate receptors that are largely confined to the main bodies of synaptic active zones (Bernard et al., 1997; Ottersen and Landsend, 1997) and mediate fast synaptic transmission.

It is noteworthy that a substantial level of intracellular AMPA glutamate receptor subunits immunoreactivity has recently been found in dendrites of dorsal cochlear neurons in rats (Rubio and Wenthold, 1999). Interestingly, the receptor subunit labeling was often found in clusters of 2-12 gold particles associated with vesicular structures that strikingly resemble the large organelles immunoreactive for KAR subunits observed in the present study (Rubio and Wenthold, 1999). Although Rubio and Wenthold (1999) showed that some of these structures displayed immunoreactivity for specific markers of endoplasmic reticulum, the majority of labeling was found over elements that were not immunoreactive for ER markers. Future studies are essential to better characterize the exact nature of these glutamate receptor packaging organelles. Presynaptic delta opioid receptors are also expressed on the membrane of large vesicles in primary afferents to the rat spinal cord (Zhang et al., 1998). Whether these vesicles represent an early stage of endosomes and/or a different type of dense-core vesicles remains to be established.

A substantial proportion of presynaptic and postsynaptic gold labeling was also associated with asymmetric synapses, suggesting that kainate receptors may mediate fast excitatory transmission at some glutamatergic synapses in the monkey striatum. However, recent electrophysiological studies could not demonstrate any synaptic activation of kainate receptors after stimulation of striatal glutamatergic afferents (Chergui et al., 2000). At present, there is no clear explanation for this apparent discrepancy between anatomical and functional data. However, these two sets of 

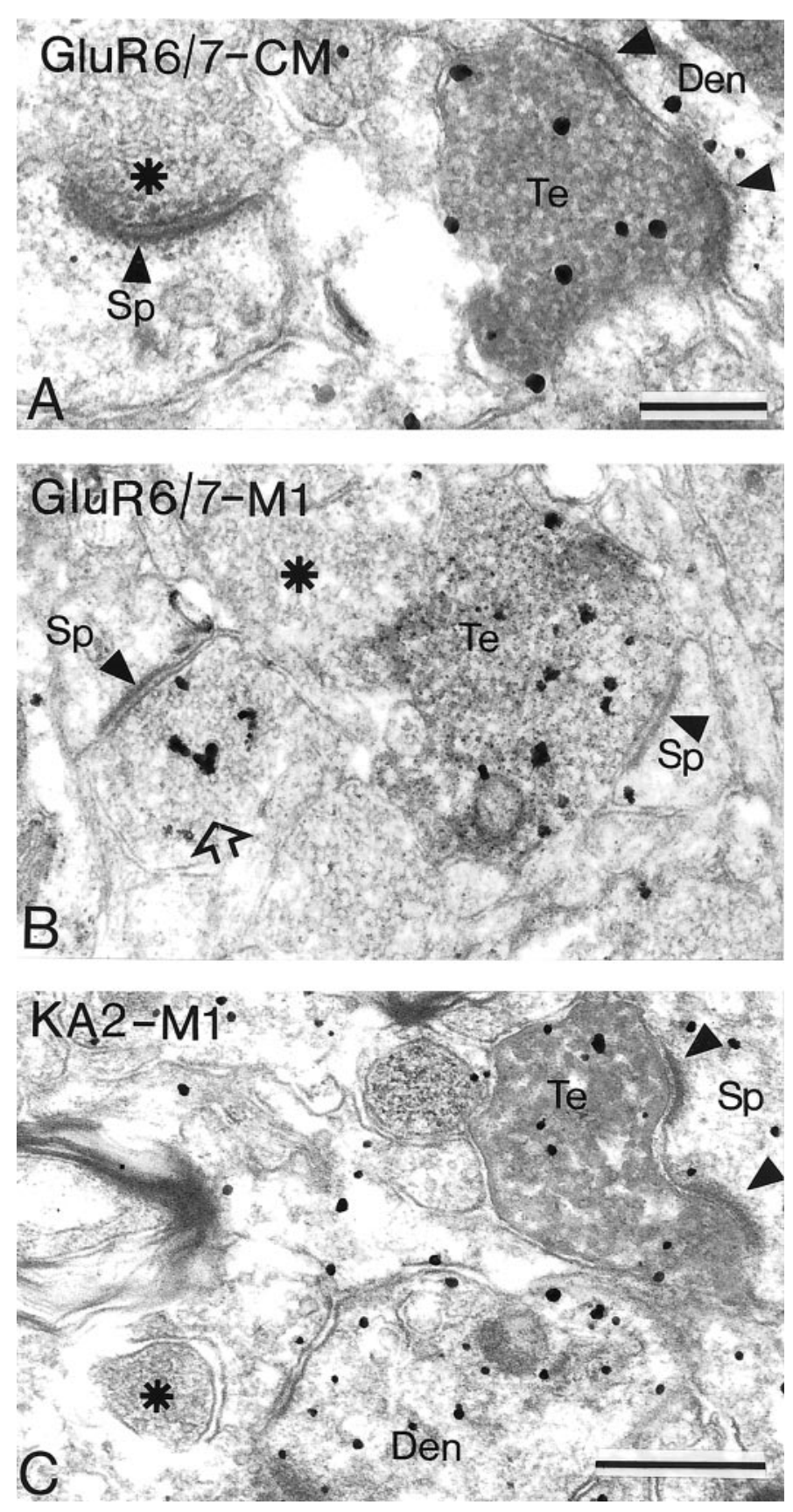

Figure 9. GluR6/7-immunoreactive $(A, B)$ and KA2-immunoreactive $(C)$ terminals $(T e)$ labeled anterogradely from the centromedian thalamic nucleus $(C M)$ or the primary motor cortex $(M 1)$ in the putamen. Nonimmunoreactive terminals are indicated by asterisks. Arrowheads point to asymmetric synapses. The open arrow indicates an unlabeled bouton that displays GluR6/7 immunoreactivity. Scale bars: $A, 0.25 \mu \mathrm{m}$ (valid for $B$ ); $C, 0.5 \mu \mathrm{m}$.

findings, combined with those obtained in other brain regions (see below), indicate that the distribution and role of kainate receptors in the CNS are different and likely to be much more complex that those of conventional ionotropic glutamate receptors.

\section{Potential functions of presynaptic striatal kainate receptors}

The roles of kainate receptors in the striatum are poorly known. However, the toxic effects of kainic acid for striatal projection neurons have long been established although the exact mecha- nism by which kainic acid induces striatal cell death is still unknown. In this regard, it is noteworthy that the excitotoxic effects of kainic acid for striatal neurons are abolished after decortication (Biziere and Coyle, 1979), which indicates that the glutamatergic corticostriatal projection is somehow involved in mediating this effect. In addition, the fact that striatal cultures become sensitive to kainic acid only when cocultured with cortical neurons is further evidence for the involvement of corticostriatal afferents (Campochiaro and Coyle, 1978; Panula, 1980). In line with these early observations, our data demonstrate that kainate receptors are, indeed, associated presynaptically and postsynaptically with corticostriatal terminals in monkeys. Classically, postsynaptic AMPA and kainate receptors are ligand-gated ion channels permeable to cations, such that activation of these receptors leads to increased $\mathrm{Na}^{+}$and $\mathrm{Ca}^{2+}$ conductances, and thus neuronal membrane depolarization. If the presynaptic kainate receptors are similar to their postsynaptic counterparts, depolarization of the nerve terminal plasma membrane could conceivably facilitate the opening of $\mathrm{Ca}^{2+}$ channels linked to glutamate release on arrival of an action potential, and thus potentiate the release of glutamate. Interestingly, recent evidence indicates that activation of GluR6-containing presynaptic kainate receptors facilitates glutamate exocytosis from cerebral cortex nerve terminals in a synaptosome preparation (Perkinton and Sihra, 1999). Similarly, kainate acts at presynaptic receptors to increase GABA release from hypothalamic neurons (Liu et al., 1999). However, kainate was found to downregulate GABAergic transmission in the rat hippocampus (Rodriguez-Moreno et al., 1997). These findings suggest that the effects of presynaptic kainate receptors are strongly dependent on the neuronal type in which they are expressed. It is likely that the mechanisms of action of kainate receptors are also complex and different from one neuronal population to another. For instance, it seems that the presynaptic inhibition of GABA release in the hippocampus is independent of ion channel activity but rather involves the activation of phospholipase $\mathrm{C}$ and protein kinase $\mathrm{C}$ (PKC) through a Pertussis toxinsensitive G-protein (Rodriguez-Moreno and Lerma, 1998). One could speculate that the facilitatory effects observed in the cereberal cortex and hypothalamus are mediated via increased calcium conductances in the membrane of the nerve terminals and/or activation of a pool of PKC that facilitates neurotransmitter release. Whether any of these effects are suitable to explain the functions of kainate receptors in the striatum remains to be established.

At first glance, it appears reasonable to believe that presynaptic kainate receptors facilitate glutamate release in the striatum, which might explain why the excitotoxic effects of kainic acid are dependent on the presence of cortical afferents. One could also speculate that the malfunctioning of such receptors in some HD patients might lead to an increased release of glutamate and excitotoxic cell death. However, a recent in vitro slice preparation study showed that kainate receptors could not be activated neither by a single or repetitive stimulation of glutamatergic afferents in the rat striatum (Chergui et al., 2000). The authors rather demonstrated that kainate receptors depress GABAergic synaptic transmission indirectly via release of adenosine acting on A2a receptors (Chergui et al. 2000). These data are surprising and difficult to reconcile with our electron microscopic findings showing the abundance of presynaptic kainate receptors in both cortical and thalamic glutamatergic afferents (Charara et al., 1999). However, the physiological conditions under which these kainate receptors are activated remains to be determined. If, under the 
experimental conditions used by Chergui et al. (2000), kainate receptors remained in intracellular compartments rather than on the plasma membrane, their lack of responses to stimulation of glutamatergic afferents is not surprising. Future studies are essential to elucidate this issue.

\section{Concluding remarks}

In conclusion, it appears that kainate receptors underlie novel modulatory functions of synaptic transmission. Their extrasynaptic localization combined with metabotropic-like effects shown in the hippocampus suggest that these receptors probably mediate slow modulatory effects rather than fast synaptic transmission. The evidence that the gene encoding the GluR6 subunit might be affected in a subset of HD patients highlights the importance of these receptors in striatal functions in normal and pathological conditions. The use of selective antagonists for kainate and AMPA receptors in normal animals, knock-out mice, and animal model of neurodegenerative diseases will certainly prove useful to clearly assess the role of kainate receptors in the striatum.

\section{REFERENCES}

Altschul SF, Madden TL, Schaffer AA, Zhang J, Zhang Z, Miller W, Lipman DJ (1997) Gapped BLAST and PSI-BLAST: a new generation of protein database search programs. Nucleic Acids Res 25:3389-3402.

Anwyl R (1999) Metabotropic glutamate receptors: electrophysiological properties and role in plasticity. Brain Res Rev 29:83-120.

Aronin N, Chase K, Young C, Sapp E, Schwarz C, Matta N, Kornreich R, Landwehrmeyer B, Bird E, Beal MF, Vonsattel JP, Smith T, Carraway R, Boyce FM, Young AB, Penney JB, DiFiglia M (1995) CAG expansion affects the expression of mutant huntingtin in the Huntington's disease brain. Neuron 15:1193-1201.

Baude A, Nusser Z, Roberts JD, Mulvihill E, McIlhinney RAJ, Somogyi P (1993) The metabotropic glutamate receptor (mGluR1a) is concentrated at perisynaptic membrane of neuronal subpopulations as detected by immunogold reaction. Neuron 11:771-787.

Bernard V, Somogyi P, Bolam JP (1997) Cellular, subcellular, and subsynaptic distribution of AMPA-type glutamate receptor subunits in the neostriatum of the rat. J Neurosci 17:819-833.

Bernard V, Levey AI, Bloch B (1999) Regulation of the subcellular distribution of $\mathrm{m} 4$ muscarinic acetylcholine receptors in striatal neurons in vivo by the cholinergic environment: evidence for regulation of cell surface receptors by endogenous and exogenous stimulation. J Neurosci 19:10237-10249.

Biziere K, Coyle JT (1979) Effects of cortical ablation on the neurotoxicity and receptor binding of kainic acid in striatum. J Neurosci Res 4:383-398.

Blackstad TW, Karagulle T, Ottersen OP (1990) Morforel, a computer program for two-dimensional analysis of micrographs of biological specimens, with emphasis on immunogold preparations. Comput Biol Med 20:15-34.

Campochiaro P, Coyle JT (1978) Ontogenetic development of kainate neurotoxicity: correlates with glutamatergic innervation. Proc Natl Acad Sci USA 75:2025-2029.

Cartmell J, Schoepp DD (2000) Regulation of neurotransmitter release by metabotropic glutamate receptors. J Neurochem 75:889-907.

Castillo PE, Maalenka RC, Nicoll RA (1997) Kainate receptors mediate a slow postsynaptic current in hippocampal CA3 neurons. Nature 388:182-186.

Charara A, Blankstein E, Smith Y (1999) Presynaptic kainate receptors in the monkey striatum. Neuroscience 91:1195-1200.

Chergui K, Bouron A, Normand E, Mulle C (2000) Functional GluR6 kainate receptors in the striatum: indirect downregulation of synaptic transmission. J Neurosci 20:2175-2182.

Chittajallu R, Braithwaite SP, Clarke VRJ, Henley JM (1999) Kainate receptors: subunits, synaptic localization and function. Trends Pharmacol Sci 20:26-35.

Clarke VRJ, Ballyk BA, Hoo KH, Mandelzys A, Pellizzari A, Bath CP, Thomas J, Sharpe EF, Davies CH, Ornstein PL, Schoepp DD, Kamboj RK, Collingridge GL, Lodge D, Bleakman D (1997) A hippocampal GluR5 kainate receptor regulating inhibitory synaptic transmission. Nature 389:599-603.

Conn PJ, Pin J-P (1997) Pharmacology and functions of metabotropic glutamate receptors. Annu Rev Pharmacol Toxicol 37:205-237.

Contractor A, Swanson GT, Sailer A, O'Gorman S, Heinemann SF (2000) Identification of the kainate receptor subunits underlying mod- ulation of excitatory synaptic transmission in the CA3 region of the hippocampus. J Neurosci 20:8269-8278.

Coyle JT, Schwarcz R (1976) Lesion of striatal neurones with kainic acid provides a model for Huntington's chorea. Nature 263:244-246.

Debonnel G, Weiss M, de Montigny C (1989) Reduced neuroexcitatory effect of domoic acid following mossy fiber denervation of the rat dorsal hippocampus: further evidence that toxicity of domoic acid involves kainate receptor activation. Can J Physiol Pharmacol 67:904-908.

Frerking M, Nicoll RA (2000) Synaptic kainate receptors. Curr Opin Neurobiol 10:342-351.

Hanson JE, Smith Y (1999) Group I metabotropic glutamate receptors at GABAergic synapses in monkeys. J Neurosci 19:6488-6496.

Hollmann M, Heinemann S (1994) Cloned glutamate receptors. Annu Rev Neurosci 17:31-108.

Hsu SM, Raine L, Fanger H (1981) Use of avidin-biotin-peroxidase complex $(\mathrm{ABC})$ in immunoperoxidase techniques: a comparison between ABC and unlabeled antibody (PAP) procedures. J Histochem Cytochem 21:557-580.

Kamiya H, Ozawa S (2000) Kainate receptor-mediated presynaptic inhibition at the mouse hippocampal mossy fibre synapse. J Physiol (Lond) 523:653-665.

Kieval JZ, Charara A, Paré J-F, Smith Y (2000) Subcellular localization of kainate receptors in the monkey striatum. Soc Neurosci Abstr 26:741.15.

Lerma J, Morales M, Vicenter MA, Herreras O (1997) Glutamate receptors of the kainate type and synaptic transmission. Trends Neurosci 20:9-12.

Liu Q-S, Patrylo PR, Gao X-B, van den Pol AN (1999) Kainate acts at presynaptic receptors to increase GABA release from hypothalamic neurons. J Neurophysiol 82:1059-1062.

Lujan R, Nusser Z, Roberts JDB, Shigemoto R, Somogyi P (1996) Perisynaptic location of metabotropic glutamate receptors mGluR 1 and mGluR5 on dendrites and dendritic spines in the rat hippocampus. Eur J Neurosci 8:1488-1500.

MacDonald ME, Vonsattel JP, Shrinidhi J, Couropmitree NN, Cupples LA, Bird ED, Gusella JF, Myers RH (1999) Evidence for the GluR6 gene associated with younger onset age of Huntington's disease. Neurology 53:1330-1332.

Matsubara A, Laake JH, Davanger S, Usami S-I, Otterson OP (1996) Organization of AMPA receptor subunits at a glutamate synapse: a quantitative immunogold analysis of hair cell synapses in the rat organ of Corti. J Neurosci 16:4457-4467.

McGeer EG, McGeer PL (1976) Duplication of biochemical changes of Huntington's chorea by intrastriatal injections of glutamic and kainic acids. Nature 263:517-519.

McGeer EG, McGeer PL, Ssingh K (1978) Kainate-induced degeneration of neostriatal neurons: dependency upon corticostriatal tract. Brain Res 139:381-383.

Min M-Y, Melyan Z, Kullmann D (1999) Synaptically released glutamate reduces $\gamma$-aminobutyric acid (GABA) ergic inhibition in the hippocampus via kainate receptors. Proc Natl Acad Sci USA 96:9932-9937.

Mulle C, Sailer A, Pérez-Otaño I, Dickinson-Anson H, Castillo PE, Bureau I, Maron C, Gage FH, Mann JR, Bettler B, Heinemann SF (1998) Altered synaptic physiology and reduced susceptibility to kainate-induced seizures in GluR6-deficient mice. Nature 392:601-605.

Nusser Z, Roberts JDB, Baude A, Richards JG, Sieghart W, Somogyi P (1995a) Immunocytochemical localization of a1 and b2/3 subunits of the GABA-A receptor in relation to specific GABAergic synapses in the dentate gyrus. Eur J Neurosci 7:630-646.

Nusser Z, Roberts JDB, Baude A, Richards JG, Somogyi P (1995b) Relative densities of synaptic and extrasynaptic GABAA receptors on cerebellar granule cells as determined by a quantitative immunogold method. J Neurosci 15:2948-2960.

Nyiri G, Freund TF, Somogyi P (2001) Input-dependent synaptic targeting of $\alpha 2$-subunit-containing $\mathrm{GABA}_{\mathrm{A}}$ receptors in synapses of hippocampal pyramidal cells of the rat. Eur J Neurosci 13:428-442.

Ottersen OP, Landsend AS (1997) Organization of glutamate receptors at the synapse. Eur J Neurosci 9:2219-2224.

Panula PA (1980) A fine structural and histochemical study on the effect of kainic acid on cultured neostriatal cells. Brain Res 181:185-190.

Pasquini F, Bochet P, Garbay-Jaureguiberry C, Roques BP, Rossier J, Beaudet A (1992) Electron microscopic localization of photoaffinitylabelled delta opioid receptors in the neostriatum of the rat. J Comp Neurol 326:229-244.

Paternain AV, Morales M, Lerma J (1995) Selective antagonism of AMPA receptors unmasks kainate receptor-mediated responses in hippocampal neurons. Neuron 14:185-189.

Penney JB, Vonsattel J-P, MacDonald ME, Gusella JF, Myers RH (1997) CAG repeat number governs development rate of pathology in Huntington's disease. Ann Neurol 41:689-692.

Perkinton MS, Sihra TS (1999) A high-affinity presynaptic kainate-type glutamate receptor facilitates glutamate exocytosis from cerebral cortex nerve terminals (synaptosomes). Neuroscience 90:1281-1292.

Persichetti F, Srinidhi J, Kanaley L, Ge P, Myers RH, D’Arrigo K, Barnes 
GT, MacDonald ME, Vonsattel JP, Gusella JF (1994) Huntington's disease CAG trinucleotide repeats in pathologically confirmed postmortem brains. Neurobiol Dis 1:159-166.

Petralia RS, Wang Y-X, Wenthold RJ (1994) Histological and ultrastructural localization of the kainate receptor subunits, KA2 and GluR6/7, in the rat nervous system using selective antipeptide antibodies. J Comp Neurol 349:85-110.

Reynolds ES (1963) The use of lead citrate at high $\mathrm{pH}$ as an electron opaque stain in electron microscopy. J Cell Biol 17:208-212.

Rodriguez-Moreno A, Lerma J (1998) Kainate receptor modulation of GABA release involves a metabotropoic function. Neuron 20:1211-1218.

Rodriguez-Moreno A, Herreras O, Lerma J (1997) Kainate receptors presynaptically downregulate GABAergic inhibition in the rat hippocampus. Neuron 19:893-901.

Rubinsztein DC, Leggo J, Chiano M, Dodge A, Norbury G, Rosser E, Craufurd D (1997) Genotypes at the GluR6 kainate receptor locus are associated with variation in the age of onset of Huntington disease. Proc Natl Acad Sci USA 94:3872-3876.

Rubio ME, Wenthold RJ (1999) Differential distribution of intracellular glutamate receptors in dendrites. J Neurosci 19:5549-5562.

Sadikot AF, Parent A, Smith Y, Bolam JP (1992) Efferent connections of the centromedian and parafascicular thalamic nuclei in the squirrel monkey: a light and electron microscopic study of the thalamostriatal projection in relation to striatal heterogeneity. J Comp Neurol 320:228-242

Shink E, Bevan MD, Bolam JP, Smith Y (1996) The subthalamic nucleus and the external pallidum: two tightly interconnected structures that control the output of the basal ganglia in the monkey. Neuroscience 73:335-357.

Sidibé M, Smith Y (1996) Differential synaptic innervation of striatofugal neurones projecting to the internal or external segments of the globus pallidus by thalamic afferents in the squirrel monkey. J Comp Neurol 365:445-465.

Sidibé M, Bevan MD, Bolam JP, Smith Y (1997) Efferent connections of the internal globus pallidus in the squirrel monkey: I. Topography and synaptic organization of the pallidothalamic projection. J Comp Neurol 382:323-347.

Smith Y, Bennett BD, Bolam JP, Parent A, Sadikot AF (1994) Synaptic relationships between dopaminergic afferents and cortical or thalamic input in the sensorimotor territory of the striatum in monkeys. J Comp Neurol 344:1-19.

Smith Y, Charara A, Hanson JE, Paquet M, Levey AI (2000) GABA $_{B}$ and group I metabotropic glutamate receptors in the striatopallidal complex in primates. J Anat 196:555-576.

Smith Y, Charara A, Paquet M, Kieval JZ, Paré J-F, Hanson JE, Hubert GW, Kuwajima M, Levey AI (2001) Ionotropic and metabotropic GABA and glutamate receptors in primate basal ganglia. J Chem Neuroanat 22:13-42.

Valtschanoff JG, Weinberg RJ (2001) Laminar organization of the NMDA receptor complex within the postsynaptic density. J Neurosci 21:1211-1217.

Vignes M, Collingridge GL (1997) The synaptic activation of kainate receptors. Nature 388:179-182.

Vonsattel JPG, DiFiglia M (1998) Huntington disease. J Neuropathol Exp Neurol 57:369-384.

Wang H, Moriwaki A, Wang JB, Uhl GR, Pickel VM (1997) Ultrastructural immunocytochemical localization of $\mu$-opioid receptors in dendritic targets of dopaminergic terminals in the rat caudate-putamen nucleus. Neuroscience 81:757-771.

Wenthold RJ, Trump VA, Zhu WS, Petralia RS (1994) Biochemical and assembly properties of GluR6 and KA2, two members of the kainate receptor family, determined with subunit-specific antibodies. J Biol Chem 269:1332-1339.

Zhang X, Bao L, Arvidsson U, Elde R, Hökfelt T (1998) Localization and regulation of the delta-opioid receptor in dorsal root ganglia and spinal cord of the rat and monkey: evidence for association with the membrane of large dense-core vesicles. Neuroscience 82:12251242. 